\title{
Pengaruh Terapi Kelompok terhadap Peningkatan Kualitas Hidup Penderita Kusta: Literature Review
}

\author{
Ernawati Hatuwe ${ }^{1}$, Arlina Dewi ${ }^{2}$ \\ ${ }^{1}$ Master of Nursing, Postgraduate Studies, Universitas Muhammadiyah Yogyakarta \\ ${ }^{2}$ Master of Hospital Managemant Postgraduate Studies, Universitas Muhammadiyah Yogyakarta \\ Email: hatuwetunny0274@gmail.com
}

\begin{abstract}
Leprosy is an infectious disease that causes very complex problems. The quality of life of people affected by leprosy is a matter that needs to be considered, Quality of life (QOL) includes physical health, psychological health, level of independence, social occupancy, personal trust, and relationships with the environment. How to improve the quality of life for lepers. Method: Search from 3 databases namely Pubmed, ProQuest and Google Cindekia using keywords of quality of life or Qol or hqrl and leprosy or morbus hansen or leprae or leprosy and self help groups or mutual-help groups or support group or therapy group or self concept This review identified 10 articles that fit the inclusion criteria. Most articles use quantitative, namely cross-sectional design, 6 articles and 1 article using quasi-experiment, 2 qualitative articles and 1 review literature article. Of the 10 articles selected, 4 articles focused on the quality of life for people affected by leprosy and 6 articles that discussed improving the quality of life for people affected by leprosy. Group therapy can improve the quality of life of people affected by leprosy and make leprosy sufferers have a deeper confidence in facing the community or the environment around
\end{abstract}

Keywords: Quality of life, leprosy, self help group

\section{PENDAHULUAN}

Penyakit kusta atau biasa di sebut hansen telah menyerang manusia sepanjang sejarah. Banyak para ahli percaya bahwa tulisan pertama tentang kusta muncul dalam sebuah dokumen Papirus Mesir ditulis sekitar tahun 1550 SM. Pada tahun 600 SM, ditemukan tulisan berbahasa India yang mengambarkan penyakit menyerupai kusta. Pada tahun 1873, Dr Gerhard Armauer Hernrik Hansen dari Norwegia. Beliau adalah orang pertama yang menemukan kuman Mycrobacterium Leprae dan mengindetifikasi kuman ini yang menyebabkan penyakit kusta (Pusat Data dan Informasi Kementerian Kesehatan RI, 2015)

Penyakit kusta atau lepra atau penyakit Hansen merupakan penyakit infeksi kronis yang disebabkan oleh bakteri Mycobacterium leprae dan utamanya mempengaruhi kulit, saraf tepi, mukosa saluran pernafasan atas dan mata. Bakteri lepra mengalami proses pembelahan cukup lama antara 2-3 minggu, daya tahan hidup di luar tubuh manusia mencapai 9 hari, dan memiliki masa inkubasi 2-5 tahun bahkan bisa lebih dari 5 tahun. Penatalaksanaan kasus kusta yang buruk dapat menyebabkan kusta menjadi progresif, menyebabkan kerusakan permanen pada kulit, saraf, anggota gerak, dan mata (Kemenkes RI, 2018)

World Health Organization (WHO) melaporkan jumlah penderita kusta dari 38 negara adalah sebanyak 176.176 kasus di akhir tahun 2015 atau 0,18 kasus per 10.000 penduduk dengan 211.973 kasus baru atau 0,21 kasus per 10.000 penduduk (www.who.int, Leprosy Fact Sheet, Updated Februari 2017). Prevalensi tetinggi terjadi di negara-negara berpenghasilan rendah dan menengah seperti India, Brasil, Myanmar, Madagaster, Nepal dan Mozambik (Santos, et al., 2015)

Kusta menimbulkan beban yang tinggi bagi masyarakat (Susanto, 2017). masyarakat beranggapan bahwa penyakit ini adalah penyakit kutukan dan menular, ini adalah masalah yang kompleks, dimana penderita kusta tidak hanya bermasalah pada segi medis, tetapi juga masalah fisik, hubungan sosial, psikologis (Hane \& Arsin, 2017). Sikap dan prilaku masyarakat yang negatif terhadap penderita kusta sering kali mereka tidak mendapat tempat dikeluarganya maupun dilingkungan masyarakat, hal ini disebabkan karena adanya stima kurangnya pemahaman informasi tentang penyakit kusta. Sehingga masalah ini menyebabkan penderita kusta cenderung hidup menyendiri dan mengurangi kegiatan sosial dengan lingkungan sekitar (Dary \& Batubara, 2017)

Kualitas hidup (QOL) meliputi kesehatan fisik, kesehatan psikologis, tingkat kemandirian, hunungan sosial, kepercayaan pribadi, dan hubungan dengan lingkungan (Savassi, Bogutchi, Lima, \& Modena, 2014). Pengukuran kualiatas hidup terhadap penderita kusta diharapkan menjadi dasar pertimbangan dalam intervensi dan penanggulangan masalah kusta tidak hanya berfokus pada fisik saja tetapi perlu diperhatikan faktor lain yang bisa mengakibatkan penurunan kualitas hidup penderita kusta (Hane \& Arsin, 2017)

\section{METODE PENELITAN Tujuan}

Untuk mereview artikel atau literatur publikasi yang menyadiaka informasi tentang kualitas hidup penderita kusta. Tujuan dari literatur ini yaitu: Cara meningkatkan kualitas hidup penderita kusta?

\section{Metode}

Pada literatur ini pencarian dibatasi 5 tahun terakhir, 2014-2018, Database yang digunakan untuk mencari jurnal Pubmed, ProQuest dan Google Cindekia untuk memastika penelitian yang terinklude up-to-date. Menggunakan kata kunci:

1. "Quality of life" or "QoL" or "hrql" or welfare

2. AND "leprosy" or "kusta" or "lepers" or "hansen disease" or "leprae"

3. AND "self help group" or "mutual-help group" or "support group" or therapy group" or "self concept

4. 1 and 2 and 3 (combined with "and")

\section{Kriteria inklusi dan eksklusi}


Kriteria inklusi artikel penelitian yang di publikasi dalam bahasa inggris dan indonesia, dipublikasi 5 tahun terakhir, abstrak, full text, dan artikel yang relevan dengan topik. Sedangkan yang diekslusi artikel yang tidak membahas tentang penyakit kusta, terdapat kesamaan judul di tiga pencarian database, fokus pada kualitas hidup dengan penyakit lain, dan literatur review yang bukan penelitian

\section{Sumber Data dan Pencarian}

Proses pencarian dilaksanakan selama periode 2016-2018. Semua detail dari identifikasi dan proses pemilihan ditunjukan dalam sebuah figure 1. Adapun jurnal Internasional yang tersedia untuk umum yang dipublikasi menggunakan bahasa inggris dan juga ada jurnal nasional yang telah dipublikasi.

Artikel yang dikeluarkan karena tidak sesuai dengan kriteria inklusi seperti penyakit lain yang tidak ada hubungan dengan kriteria yang di inginkan

\section{HASIL DAN PEMBAHASAN}

Tabel 1. Proses Pemilihan
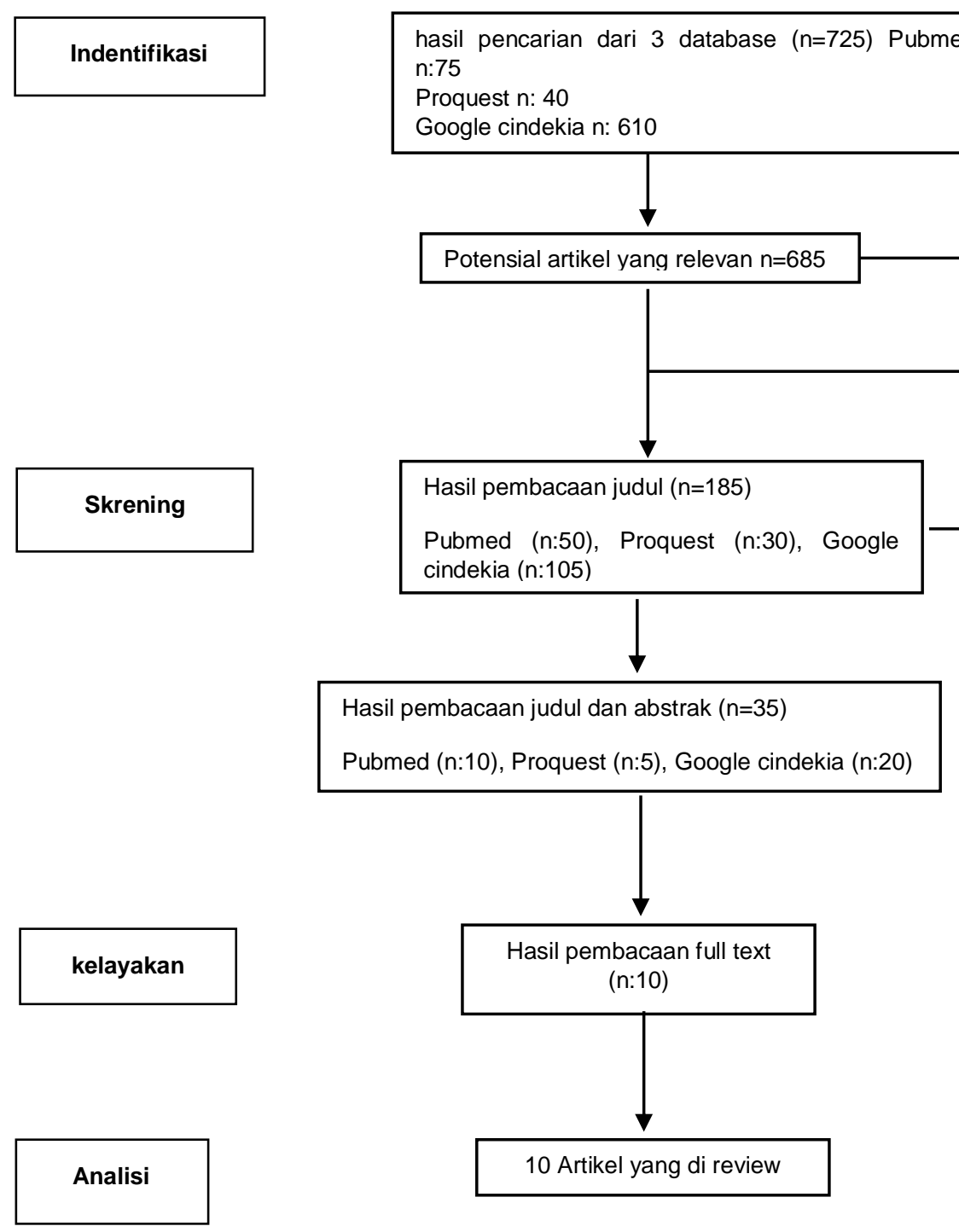

Tabel 2. Ringkasan semua artikel

\begin{tabular}{|c|c|c|c|c|c|}
\hline No & Penulis Tahun & Tujuan & Partisipan /sample & $\begin{array}{l}\text { Desain dan metode } \\
\text { pengumpulan data }\end{array}$ & Hasil \\
\hline 1 & $\begin{array}{l}\text { Leonardo Canc, et } \\
\text { al., } 2014\end{array}$ & $\begin{array}{l}\text { Untuk mengevaluasi } \\
\text { kualitas hidup dari } \\
\text { bawaan sekuel kusta } \\
\text { dan faktor-faktor } \\
\text { yang dapat } \\
\text { mempengaruhi } \\
\text { persepsi tentang } \\
\text { kondisi mereka. }\end{array}$ & $\begin{array}{lr}\text { Ada } 32 \text { responden yang } \\
\text { diberi } & \text { kuesioner } \\
\text { WHOQoL-BREF } & \text { yang } \\
\text { tinggal } & \text { daerah } \\
\text { jangkauan } & \text { bekas } \\
\text { leprosarium } & \end{array}$ & $\begin{array}{l}\text { sebuah studi cross- } \\
\text { sectional, diRumah } \\
\text { Sakit santa Izabel. } \\
\text { menggunakan } \\
\text { kuesioner }\end{array}$ & $\begin{array}{l}\text { Individu yang terkena kusta } \\
\text { memiliki skor kualitas hidup yang } \\
\text { rendah. Dan faktor yang } \\
\text { mempengaruhi kualitas hidup } \\
\text { mereka terkait dengan kondisi fisik } \\
\text { dan psikologis mereka. }\end{array}$ \\
\hline 2 & $\begin{array}{l}\text { Reny Nugraheni; } \\
2016\end{array}$ & $\begin{array}{lr}\text { Untuk mengetahui } \\
\text { analisis } & \text { konsep diri } \\
\text { terhadap } \quad \text { kualitas } \\
\text { hidup penderita kusta } \\
\text { yang mengalami }\end{array}$ & $\begin{array}{l}97 \text { responden } \\
\text { penelitian ini }\end{array}$ & $\begin{array}{l}\text { Analitik opservasional } \\
\text { dengan pendekatan } \\
\text { cross-sectional. }\end{array}$ & $\begin{array}{l}\text { Analisis terbukti bahwa ada } \\
\text { hubungan konsep diri terhadap } \\
\text { kualitas hidup penderita kusta } \\
\text { yang mengalami kecacatan. } \\
\text { Konsep diri akan mempengaruhi }\end{array}$ \\
\hline
\end{tabular}


kecacatan

3

Santos Victor, et al; 2015

Hane Ode, et al; 2017

Lusli mimi, et al; Praktek modul

$2017 \quad$ konseling bertujuan untuk mengurangi stigma terkait kusta.

6 Risnawati fajar, et al; Untuk 2016

mengidentifikasi efek terapi kelompok terhadap harga diri pasien dengan kusta

7 Sermrittiron Silatham; 2014

Untuk

mengidentifikasi intervensi yang telah digunankan untuk mengurangi stigma

8 Henry, et al; 2014

Melihat perbandingan masalah sosial pasien diabetes dan pasien kusta dengan Self care group agar dapat di ingginkan dan diterima untuk peserta yang layak

9

Susanto Tantut, et Untuk memahami al; 2017

\section{pengalaman}

penderita kusta yang berpartisipasi dalam self care group dengan tujuan meningkatkan fungs untuk menyelesaikan masalah perawatan diri dimasyarakat

$\begin{array}{ll}\text { Prycel Joseph, et al; } & \text { Untuk menetukan } \\ 2018 & \text { kelayakan } \\ & \text { mengintegrasikan } \\ & \text { orang-orang yang } \\ & \text { terkena dampak } \\ & \text { limfedema filaria } \\ & \text { dalam self help group } \\ & \text { kusta r r }\end{array}$

104 responden yang ada di pusat rujukan spesialis di Sergipe Brazil, antara Juni dan Oktober 2014

Populasi 87 orang sample 72 penderita kusta yang diambil secara purposive sampling

53 partisipan

14 responden yang dirawat inap di RS Kusta Kediri

55 makalah dibaca dan hanya 25 makalah yang masuk dalam kriteria

41 pasien diabetes dan 31 pasien kusta

17 peartisipan dari dua komunitas self care group.

Peserta 105 (peserta limfedema filaria 52 dan peserta kusta 53) cross-sectional menggunakan kuesioner Organisasi Kesehatan DuniaQoL-BREF (WHOQoL-BREF)

Jenis penelitian observasi analitik dengan desain Crosssectional

\section{Metode} digunakan kualitatif.

desain eksperimental dengan intervensi satu kelompok

Pencarian jurnal di Pubmed (Medline), CINAHL, Psych Info dan Google Cindekia

Desain digunakan deskrptif cross-sectionl

Desain digunakan ini adalah kualitatif. dikumpulkan menggunakan panduan wawancara semi-terstruktur

Desain survei cross sectional. Menggunakan kuesioner terstruktur dan dilakukan dalam skenario wawancara menggunakan asisten peneliti lokal yang membacakan pertanyaan kepada peserta. diri seseorang dalam melakukan kontak komunikasi atau interaks dengan orang lain.

Ada hubungan antara aktivitas fungsional dengan kualitas hidup pasien kusta selama dan setelah perawatan.

Faktor yang dapat mempengaruhi kualitas hidup penderita kusta meliputi jenis kusta, kecacatan, dan Depresi salah satu faktor yang mempengaruhi kualitas hidup penderita kusta.

Penelitian ini menunjukan bahwa lima sesi konseling dapat mengurangi stigma pada penderita kusta.

ada perbedaan harga diri yang signifikan antara sebelum dan sesudah intervensi. Pasien dengan kusta perlu mengubah perseps negatif mereka agar dapat beradaptasi secara positif.

Intervensi dengan beberapa bukt efektivitas dalam pengurangan stigma terdiri dari integras programmer kusta didalam perawatan kesehatan umum, programmer pendidikan komunikasi (KIE) dan rehailitas sosial ekonomi.

Ada perbedaan antara pasien kusta dengan pasien diabetes untuk ikut kelompok perawatan. Sebagian besar pasien diabetes mengatakan tidak ingin berpartisipasi dalam kelompok perawaan diri (self care group), berbeda dengan pasien kusta mereka sangat antusias untuk ikut dalam kelompok perawatan diri karena penyakit homogen.

Self care group ini kgiatan yang sangat membantu penderita kusta dalam memenuhi kebutuhan dasar mereka dan mendorong perawatan diri, termasuk kondisi fisi, sosial, psikologis, ekonomi, budaya dan spiritual. Hal ini perlu ada pengawasan dari Perawat Kesehatan Masyarakat (PHS) dan dukungan dari keluarga agar kualitas hidup penderita kusta lebih baik.

Peserta yang terkena kusta memiliki pengetahuan baik tetang tehnik perawatan diri dan berlatih lebih sering dari pada peserta yang terkena limfedema filaria hanya seperempat dari peserta yang mengikuti self care group dan jarang berlatih.
Review ini mengidentifikasi 10 artikel yang sesuai dengan kriteria inklusi. Kebanyakan artikel menggunakan kuantitatif yaitu desain cross sectional 6 artikel dan 1 artikel menggunakan kuasi eksperimen, 2 artikel kualitatif dan 1 artikel literatur review. Dari 10 artikel yang terpilih, 4 artikel fokus pada kualitas hidup penderita kusta dan 6 artikel yang membahas tetang meningkatkan kualitas hidup penderita kusta.

\section{Cara meningkatkan kualitas hidup penderita kusta}

Review ini mengidentifikasi beberapa cara untuk meningkatkan kualitas hidup penderita kusta. 4 artikel menjelaskan tentang kualitas hidup penderita kusta dan 
6 artikel menjelaskan bagaimana meningkatkan kualitas hidup dengan menggunakan metode self help group dan ataupun mengurangi stigma.

(Santos Victor, et al; 2015), (Leonardo Canc, et al., 2014) 2 artikel menjelaskan bahwa pasien kusta memiliki kualitas hidup yang rendah, kualitas hidup dilihat dari segi kesehatan fisik, kesehatan psikologi, tingkat kemandirian, hubungan sosial, kepercayaan pribadi, dan hubungan dengan lingkungan. Pasien kusta dengan keterbatasan aktivitas dapat mengahadapi penurunan kualitas hidup.

(Reny Nugraheni; 2016), (Hane \& Arsin, 2017) penderita kusta yang mengalami kecacatan cendrung hidup menyendiri dan mengurangi kegiatan sosial dengan lingkungan disekitar, masalah yang ditimbulkan oleh penyakit kusta akan mempengaruhi kualitas hidup penderita kusta. Faktor yang dapat mempengaruhi kulitas hidup penderita kusta dapat ditinjau dari faktor karateristik demografi, depresi, isolasi disuatu lingkungan, nyeri neiropatik, stigma yang dialami oleh penderita, dukungan keluarga, dan dukungan dari petugas kesehatan.

self help group adalah cara meningkatkan kehidupan pasien kusta dengan mencegah kecacatan, juga meningkatkan pengetahuan dan praktek perawatan diri orang- orang yang memiliki penyakit yang sejenis. Terapi kelompok juga dapat meningkatkan harga diri pasien kusta dan membuat pasien lebih percaya diri dalam menghadapi masyaraka (Pryce et al., 2018), (Risnawati fajar, et al; 2016), dan (Henry, et al; 2014)

Adapun masalah yang membahas tentang mengurangi stigma pada penderita kusta. (Sermrittirong \& van Brakel, 2014), (Lusli, Peters, Bunders, Irwanto, \& Zweekhorst, 2017), dan (Susanto Tantut, et al; 2017) self care group salah satu kelompok perawatan diri yang dapat menggurangi stigma pada penderita kusta, ini juga sangat membantu untuk mengurangi komplikasi dan meningkatkan kemandirian pasien kusta selama berlangsung dan setelah program pengobatan. Pengembangan praktek dan modul konseling merupakan salah satu bentuk untuk mengurangi stigma dimana pemberian pengetahuan medis tentang kusta memainkan peran penting dalam memerangi stigma.

\section{Pembahasan}

Kualitas hidup menjadi semakin penting bagi dunia kesehatan, terkait kompleksitas hubungan biaya dan nilai dari pelayanan keperawatan kesehatan yang didapatkan. Kualitas hidup dapat diartikan sebagai persepsi individu mengenai posisi mereka dalam kehidupan budaya dan sistem nilai dimana mereka hidup dengan tujuan, harapan standar dan perhatian mereka (Nursalam, 2016)

Aspek yang kompleks dalam kehidupan yakni masalah kesehatan fisik, status psikologik, tingkat kebebasan, hubungan sosial dan lingkungan di mana mereka tinggal. Upaya yang dapat dilakukan untuk mengatasi adanya perubahan kualitas hidup diantaranya yakni dengan mencegah atau mengurangi faktor-faktor penyebabnya seperti menghilangkan stigma yang ada pada masyarakat, memberikan kesempatan yang sama pada penderita kusta untuk bersosialisasi dengan lingkungan, mencegah terjadinya komplikasi akibat kusta serta memaksimalkan peran promotif, preventif dan rehabilitatif perawat dalam mencegah penularan dan terjadinya kecacatan akibat kusta (Maziyya, Nursalam, \& Mariyanti, 2016).

Faktor-faktor yang mempengaruhi kualitas hidup penderita kusta antara lain: jenis kusta yang diderita, derajatan kecacatan akibat kusta, sanitasi yang kurang sehat, kebersihan individu, daya tahan tubuh, distres psikologis dan keterbatasan aktivitas akibat komplikasi kusta dan keterbatasan keadaan sosial ekonomi (Santos et al, 2015), kondisi tempat tinggal dan adanya isolasi dari lingkungan serta adanya stigma yang dialami oleh penderita kusta (Rahayuningsih, 2012) dalam (Hane Ode, et al, 2017).

Kuman mycobacterium leprae ditularkan melalui kontak langsung dengan penderita, kemudian masuk melalui pernapasan. Penyakit ini jika tidak segera ditangani maka akan muncul beberapa masalah seperti kecacatan mata, tangan dan kaki, hal ini memberikan dampak fisik maupun psikis pada responden, dampak fisiknya adalah berkurangnya kemampuan fungsional tubuh yang mengalami kecacatan, sedangkan dampak psikisnya adalah permasalahan konsep diri pada penderita kusta (Nugraheni, 2016)

Penyakit kusta banyak menimbulkan stigma negatif dan deskriminasi yang membutuhkan suatu penyelesaian. Stigma juga salah satu penyebab rendahnya kualitas hidup pada penderita kusta (Fajar Rinawati \& Moh Alimansur, 2016).

Beberapa cara atau metode untuk meningkatkan kualitas hidup penderita kusta yaitu metode self help group, self care group, terapi kelompok, praktek dan modul konseling berbasis hak. Dengan menggunakan metode-metode ini terbukti dapat meningkatkan kehidupan pasien sehubungan dengan pencegahan kecacatan, mengurangi stigma di masyarakat, meningkatkan kewaspadaan pada tanda-tanda awal komplikasi neuropatik, mengurangi kebutuhan untuk perawatan tambahan dan waktu perawatan rutin (de Vries, de Groot, \& van Brakel, 2014)

Adapun hambatan dalam pelaksanaan terapi kelompok yaitu penderita kusta tidak mengikuti kegiatan, malu dalam berkomunikasi, pasif dalam kelompok (Pryce et al., 2018). Dalam mengikuti kegiatan terapi kelompok ini peserta dituntut berperan aktif dan siap untuk menjadi pempimpin kelompok, berbagi pengalaman tentang penyakit yang diritanya, berfikir yang positif, dan dapat mengambil keputusan secara mandiri. Ini merupkan cara agar kualitas hidup penderita kusta lebih baik (Susanto, 2017)

\section{SIMPULAN}

Terapi kelompok dapat meningkatkan kualitas hidup penderita kusta dan membuat penderita kusta memiliki rasa percaya diri yang lebih dalam mengahadapi masyarakat atau lingkungan disekitar. Hambatan dalam melakukan terapi kelompok pada penderita kusta meliputi tidak berpartisipasi dalam mengikuti kegiatan, kurang percaya diri, merasa malu dalam komunikasi, dan pasif dalam kelompok

\section{DAFTAR PUSTAKA}

Dary, D., \& Batubara, S. O. (2017). Penderita Lepra Dan Peran Perawat Terkait Stigma Pada Penderita Lepra: Studi Fenomenologi. Media Kesehatan 
Masyarakat

Indonesia.

Indonesia, 543-553.

https://doi.org/10.1002/asna.18871160307

de Vries, H. J. C., de Groot, R., \& van Brakel, W. H. (2014). Social Participation of Diabetes and ExLeprosy Patients in the Netherlands and Patient Preference for Combined Self-Care Groups. Frontiers in Medicine, 1(August), 1-6. https://doi.org/10.3389/fmed.2014.00021

Fajar Rinawati \& Moh Alimansur. (2016), (23), 83-88.

Hane, L. O., \& Arsin, A. A. (2017). Faktor Yang Mempengaruhi Kualitas Hidup Penderita Kusta Factors Affecting Life Quality Of Leprosy Patients In Central Maluku Regency In 2017 Departemen Epidemiologi , Fakultbas Kesehatan Masyarakat Universitas Hasanuddin Departemen Epidemiologi , Fakultba, 1.

Kemenkes RI. (2018). Jumlah kasus penyakit hipertensi terbanyak di Pekanbaru tahun 2016. https://doi.org/10.1111/evo.12990

Lusli, M., Peters, R., Bunders, J., Irwanto, I., \& Zweekhorst, M. (2017). Development of a rightsbased counselling practice and module to reduce leprosy-related stigma and empower people affected by leprosy in Cirebon District, Indonesia. Leprosy Review, 88(3), 318-333.

Maziyya, N., Nursalam, \& Mariyanti, H. (2016). Kualitas Hidup Penderita Kusta Berbasis Teori Health Belief Models (HBM). Jurnal INJEC, 1(1), 96-102.

Nugraheni, R. (2016). Analisis Konsep Diri Terhadap Kualitas Hidup Penderita Kusta Yang Mengalami Kecacatan Di Rumah Sakit Kusta Kediri. Jurnal Preventia, $1 . \quad$ Retrieved from journal.um.ac.id/index.php/preventia/article/downl oad/8846/4252

Pryce, J., Mableson, H. E., Choudhary, R., Pandey, B. D., Aley, D., Betts, H., ... Cross, H. (2018). Assessing the feasibility of integration of self-care for filarial lymphoedema into existing community leprosy self-help groups in Nepal. BMC Public Health, 18(1), 1-13. https://doi.org/10.1186/s12889-018-5099-0

Pusat Data dan Informasi Kementerian Kesehatan RI. (2015). Info, Data, dan Informasi Kusta.

Santos, et al. (2015). Functional Activity Limitation and Quality of Life of Leprosy Cases in an Endemic Area in Northeastern Brazil, 1-8. https://doi.org/10.1371/journal.pntd.0003900

Savassi, L. C. M., Bogutchi, T. R. S., Lima, A. C. L., \& Modena, C. M. (2014). Quality of life of leprosy sequelae patients living in a former leprosarium under home care: univariate analysis. Quality of Life Research : An International Journal of Quality of Life Aspects of Treatment, Care and Rehabilitation, 23(4), 1345-1351. https://doi.org/10.1007/s11136-013-0590-7

Sermrittirong, S., \& van Brakel, W. H. (2014). How to reduce stigma in leprosy - a systematic literature review. Leprosy Review, 85(3), 149-157. Retrieved from http://www.lepra.org.uk/platforms/lepra/files/lr/Sept 14/1889.pdf

Susanto, et al. (2017). The experiences of people affected by leprosy who participated in self-care groups in the community: A qualitative study in 